Journal of Thermal Engineering, Vol. 6, No. 3, pp. 313-326, April, 2020

Yildiz Technical University Press, Istanbul, Turkey

\title{
CONSTRAINED GA PI SLIDING MODE CONTROL OF INDOOR CLIMATE COUPLED MIMO GREENHOUSE MODEL
}

\author{
K. Lammari ${ }^{1} 2^{*}$, F. Bounaama ${ }^{1,2}$, B. Ouradj ${ }^{1,2}$, B. Draoui ${ }^{1,2}$
}

\begin{abstract}
High accuracy trajectory tracking with constrained inputs is challenging topic in greenhouse indoor environment control. This is due to nonlinearities and inputs/outputs coupling present in physical model of greenhouse. The objective of this study is about the problem of identification and control of a Multi-Input MultiOutput (MIMO) greenhouse process. Proportional Integral (PI) and sliding mode controllers (SMC) are used in conjunction so that estimated outputs tracks desired trajectories with good performance as near as possible in spite of coupled dynamics and outside disturbances climate. To reflect the practical aspect, the constraints of the process and control elements were taken into account .The results demonstrate the feasibility of PISMC control method. Simulation has been done in the environment of Matlab and Simulink; it shows that combined controllers are capable to manage successfully the microclimate of greenhouse.
\end{abstract}

Keywords: PI, Sliding Mode Control, Greenhouse, MIMO, Microclimate Model, Constrained Inputs, Coupled Dynamics

\section{INTRODUCTION}

The greenhouse is a place where plants and vegetables are grown for commercial or research purposes. These houses are a variety of sheds of different sizes and roofing materials, such as the ceiling, walls that are glass or plastic. The temperature and vapor pressure of the air are the most important environmental factors for the physiological growth of all crops. Different crops in different development periods have different temperature and humidity requirements [1].

The realization of good tracking performance in greenhouse systems is made difficult by nonlinearities, parameter uncertainties and external climate disturbances. These characteristics are due to the effects of time-varying parameters (seasonal), coupling and interacting inputs and outputs. Most of the research on analysis and control of the environment inside greenhouses have been based on the idea of energy and mass balance and physical modelization $[2,3,4]$.

These concepts are effective in order to clarify the concepts of environmental control, but their developments are difficult and very expensive. Black box models, those that try to approximate the behavior without a priori information, like, polynomial fitting, neural networks, fuzzy sets, etc., are easier to obtain, and have good quality $[5,6,7,8]$.

This work exploits the other alternative where the inside outside climate model of the commercial greenhouse, with the regrouped data sets of Avignon, France are used to obtain the MIMO model of environmental greenhouse. This latter was utilized to simulate and test the PI sliding mode controller (PISMC). With the only conventional PI controller, a good performance characteristic can be achieved if all greenhouse model parameters and operating conditions, such as external perturbations, are known and invariant over time. However, the performance of PI controllers for indoor climate regulation is degrading under disturbances and changes in greenhouse parameters. In addition, the coefficients of the PI controller have been carefully selected to obtain the desired response. This makes the use of the traditional PI controller an unwise choice for control in MIMO and

This paper was recommended for publication in revised form by Regional Editor Mohammad Rahimi-Gorji

${ }^{1}$ University Tahri Mohamed of Bechar BP 417, Algeria

${ }^{2}$ ENERGARID Laboratory, Bechar, Algeria

*E-mail address: lammarikhelifa@yahoo.fr

Orcid id: 0000-0003-0679-5425, 0000-0003-4911-8694, 0000-0003-0313-1471, 0000-0001-5490-3991

Manuscript Received 14 March 2019, Accepted 23 June 2019 
nonlinear systems like the greenhouse. The above problems can be resolved by advanced control techniques such as slider control. Sliding mode control (SMC) has become a more common control method and a robust control technology for dealing with the uncertain and nonlinear system. This popularity is caused by high performance, even in the case of nonlinear systems and multiple inputs and outputs. In general, the system with the SMC tool is insensitive to parameter variations and external disturbances. However, this type of control possesses a disadvantage, namely the phenomenon of chattering. Various solutions have been suggested in the research literature to decrease chattering $[1,9]$.

Since being proposed by Emilyanov [2], sliding mode control has proven especially suitable for the design of robust control for many nonlinear systems with nonlinearities, parameter uncertainties and input disturbances. In this paper, a PI sliding mode controller for a coupled MIMO greenhouse model is designed and simulated. The control objective is to maintain a strongly coupled inside air temperature and inside air pressure of highly perturbed greenhouse, at specified set-points, by the ventilation/cooling and moisturizing operation. The aim of this work is to attenuate or eliminate the phenomenon of chattering by applying a combination between an optimized PI and SMC.

This document describes the experimental set-up, and the MIMO environment greenhouse model identification using genetic algorithm. The design of PI sliding mode controller was briefly reviews, and implemented on MATLAB/Simulink.

\section{EXPERIMENTALSET UP AND MODEL IDENTIFICATION USING GENETIC ALGORITHM Greenhouse system description}

Measurements of indoor-outdoor microclimate rate and simultaneous recording of climatic parameters were performed with an experimental greenhouse (Figure 1). This greenhouse is sheltered with a sole film of polyethylene equipped with rooftop and side openings and situated at the INRA bioclimatology stand Avignon, France (Lat $43^{\circ}$ $\left.55^{\prime}\right)$.

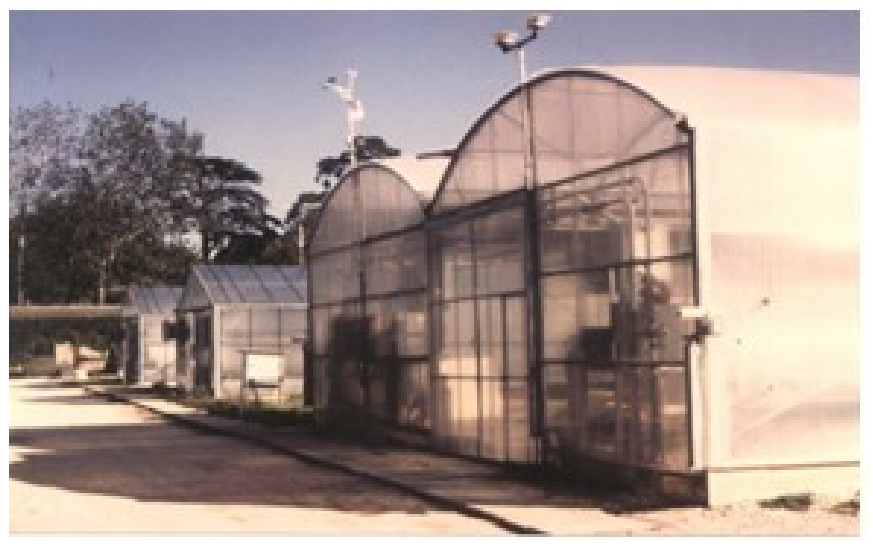

Figure 1. A view of the experimental greenhouse

Available data are collected when the greenhouse was used to grow a tomato crop on a mineral wool substrate. Wet and dry husk temperature both interior and outer the greenhouse were measured using thermocouples (precision $\pm 0.1^{\circ} \mathrm{C}$ ), solar radiation was measured by a pyranometer (precision $\pm 5 \mathrm{Wm}-2$ ), and wind speed by a cup anemometer mounted on the roof of the greenhouse. Input and control variables were sampled once a minute, but averaged over one hour due to the great inertia of the greenhouse system [10,11].

Several studies $[10,12,13,14]$ simulates models to characterize the dynamic attitude of greenhouse internal climate; these models are produced to control the climate in the greenhouse. Often, these models are created to effectively control the interior climate of greenhouses $[10,15,16,17]$. The nonlinear description of the experimental greenhouse plant is described by energy balance and water vapor equations [10].

The thermal mass relation is described by: 


$$
C_{m} \frac{d T_{m}}{d t}=h\left(T_{i}-T_{m}\right)+\beta R_{g}+Q_{s o l}
$$

where;

- $C_{m}$ is the heat capacity of the thermal mass $\left(\mathrm{Jm}^{-2} \mathrm{~K}^{-1}\right)$,

- $\frac{d T_{m}}{d t}$ is the first derivative of $\mathrm{T}_{\mathrm{m}}$ with respect to time $\left(\mathrm{Ks}^{-1}\right)$,

- his convective exchange coefficient between the air and the thermal mass $\left(\mathrm{Wm}^{-2} \mathrm{~K}^{-1}\right)$,

- $\mathrm{T}_{\mathrm{i}}$ is the internal temperature $\left({ }^{\circ} \mathrm{C}\right)$,

- $T_{m}$ is the temperature of the thermal mass $\left({ }^{\circ} \mathrm{C}\right)$,

- $\beta$ is the ratio absorption of the overall radiation by the thermal mass compartment of the greenhouse (.),

- $R_{g}$ is the outside global radiation $\left(\mathrm{Wm}^{-2}\right)$,

- $Q_{\text {sol }}$ denotes the heat soil flux $\left(\mathrm{Wm}^{-2}\right)$.

The thermal crop relation is modelled as:

$$
C_{v} \frac{d T_{v}}{d t}=h^{\prime}\left(T_{i}-T_{v}\right)
$$

where;

- $C_{v}$ is the heat-storage capacitor of the crop $\left(\mathrm{Jm}^{-2} \mathrm{~K}^{-1}\right)$,

- $\frac{d T_{v}}{d t}$ is the first derivative of $T_{v}$ with respect to time $\left(\mathrm{Ks}^{-1}\right)$,

- $h^{\prime}$ is the air/crop convective exchange parameter $\left(\mathrm{Wm}^{-2} \mathrm{~K}^{-1}\right)$,

- $T_{v}$ is the vegetable air temperature $\left({ }^{\circ} \mathrm{C}\right)$.

The air thermal balance equation is given by:

$$
0=Q_{a i r}+\alpha R_{g}+h\left(T_{m}-T_{i}\right)+h^{\prime}\left(T_{v}-T_{i}\right)+K\left(T_{e}-T_{i}\right)+K_{s}\left(T_{e}-T_{i}\right)+K_{l}\left(P_{e}-P_{i}\right)
$$

where;

- $Q_{\text {air }}$ is the internal air heating $\left(\mathrm{Wm}^{-2}\right)$,

- $\alpha$ is the report absorption of the overall radiation by the aerial compartment of the greenhouse (.),

- $T_{e}$ is the outside air temperature $\left({ }^{\circ} \mathrm{C}\right)$,

- $P_{e}$ is the partial water vapor pressure of the outside air $(\mathrm{hPa})$,

- $P_{i}$ is the partial water vapor pressure of the inside air (hPa),

- $K$ is the global heat loss parameter by greenhouse wrap $\left(\mathrm{Wm}^{-2} \mathrm{~K}^{-1}\right)$,

- $K_{s}$ is the sensible heat transfer parameter driven by ventilation $\left(\mathrm{Wm}^{-2} \mathrm{~K}^{-1}\right)$,

- $K_{l}$ is the latent heat transfer parameter resulted by ventilation $\left(\mathrm{Wm}^{-2} \mathrm{hPa}^{-1}\right)$,

- $\alpha R_{g}$ is the profit solar directly absorbed by the thermal mass $\left(\mathrm{Wm}^{-2}\right)$,

- $K\left(T_{e}-T_{i}\right)$ is the heat exchange between interior and exterior environment $\left(\mathrm{Wm}^{-2}\right)$,

- $K_{s}\left(T_{e}-T_{i}\right)+K_{l}\left(P_{e}-P_{i}\right)$ are sensible and latent heat exchanges by ventilation and leakages, and, air water vapor balance $\left(\mathrm{Wm}^{-2}\right)$, where $K_{s}$ and $K_{l}$ are a function of the following coefficients $: \rho, C_{p}$, $s, s_{0}, d_{0}, S, V, A l \sqrt{C}$ and $\gamma$ for more details see the reference [10].

The first orders air water vapor is modelled as:

$$
C_{l} \frac{d P_{i}}{d t}=\varphi_{l}+A \tau^{\prime} R_{g}+B\left(P^{*}\left(T_{i}\right)-P_{i}\right)+K_{L}\left(P_{e}-P_{i}\right)
$$

where; 
- $C_{l}$ is the equivalent thermal capacity of the water vapor of the air $\left(\mathrm{JhPa}^{-1} \mathrm{~m}^{-2}\right)$,

- $\frac{d P_{i}}{d t}$ is the first derivative of $P_{i}$ with respect to time $\left(\mathrm{hPas}^{-1}\right)$,

- $\varphi_{l}$ represent the missing of the fog system,

- $\tau^{\prime}$ is thegreenhouse covers transmittance factor (.),

- $A \tau^{\prime} R_{g}$ is the crop transpiration $\left(\mathrm{Wm}^{-2}\right)$,

- $B\left(P^{*}\left(T_{i}\right)-P_{i}\right)+K_{L}\left(P_{e}-P_{i}\right)$ are the exchanges by the crops $\left(\mathrm{Wm}^{-2}\right)$,

$$
P^{*}\left(T_{i}\right)=6.1070\left(1+\sqrt{2} \sin \left(\frac{\pi T_{i}}{540}\right)\right)^{8.827}
$$

The equation 5 represents the water vapor saturation pressure [10]. The combination of the above equations leads to a coupled MIMO model of greenhouse with four states $\left(T_{m}, T_{v}, T_{i}, P_{i}\right)$. In Figure 2, we have described a greenhouse scheme where the variables to be controlled are $T_{i}$ and $P_{i}$, the controls inputs are $Q_{\text {sol }}, Q_{a i r}$, s and $\varphi_{l}$. $\left(T_{e}, P_{e}, V, R_{g}\right)$ represent the climatic disturbances.

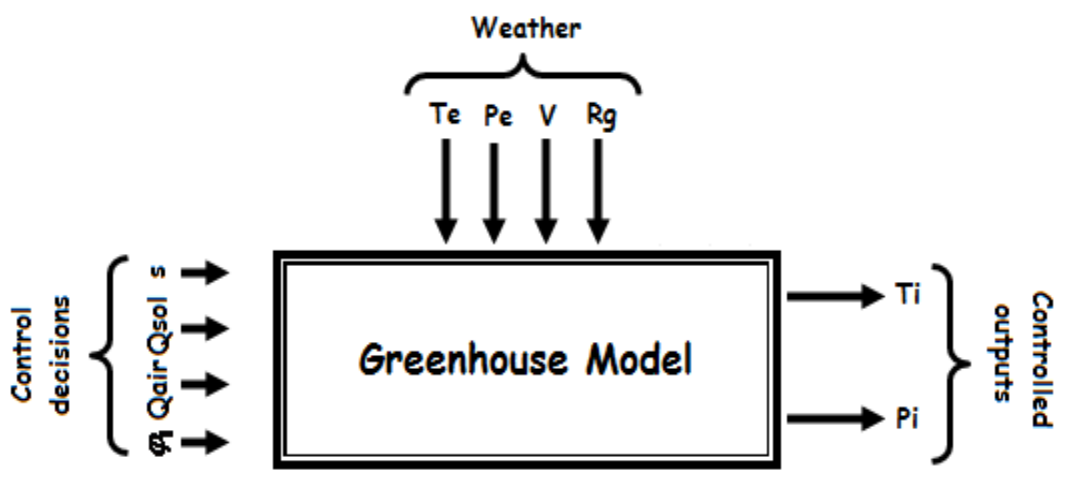

Figure 2. A schematic representation of the greenhouse system

\section{Genetic algorithm}

Genetic algorithms (GA) represent a stochastic universal search method that replicates the process of natural evolution. This is one of the methods used for optimization. John Holland officially introduced this new method in 1970 at the University of Michigan. It is inspired by the process of natural selection where stronger individuals might be the victors in a competitive environment [18]. Recently, GA has been recognized as an efficacious technique to solve optimization problems and compared with other optimization techniques. GA starts up with an initial population containing a number of chromosomes where each one represents a solution of the problem which performance is evaluated by a fitness function. Basically, GA consists of three main stages [19, 20]:

- The selection methods that includes the choice of individually named as parents (contributes to the upcoming generation).

- The crossover techniques provide parents to form children for the upcoming generation.

- The mutation techniques apply random changes to singular children.

The optimization function that has been envisaged is based on the application of these three basic operations that allow the creation of new people who can be better than their parents. This algorithm is renewed for many generations and stops when affected individuals representing the optimal solution to the problem are reached. The GA diagram is done in Figure 3.

\section{Objective function of GA}

The significative step in the designing of a genetic algorithm is the objective function. The simulated estimations of the MIMO model with the differentials equations (1-5) are compared with the experimental data [10, 
21]. The objective function of such optimization utilizes errors between estimated and measured outputs in the calibration case and between the predictions and references in the control case [22]. The GA parameters for the optimization process are exposed in Table 1:

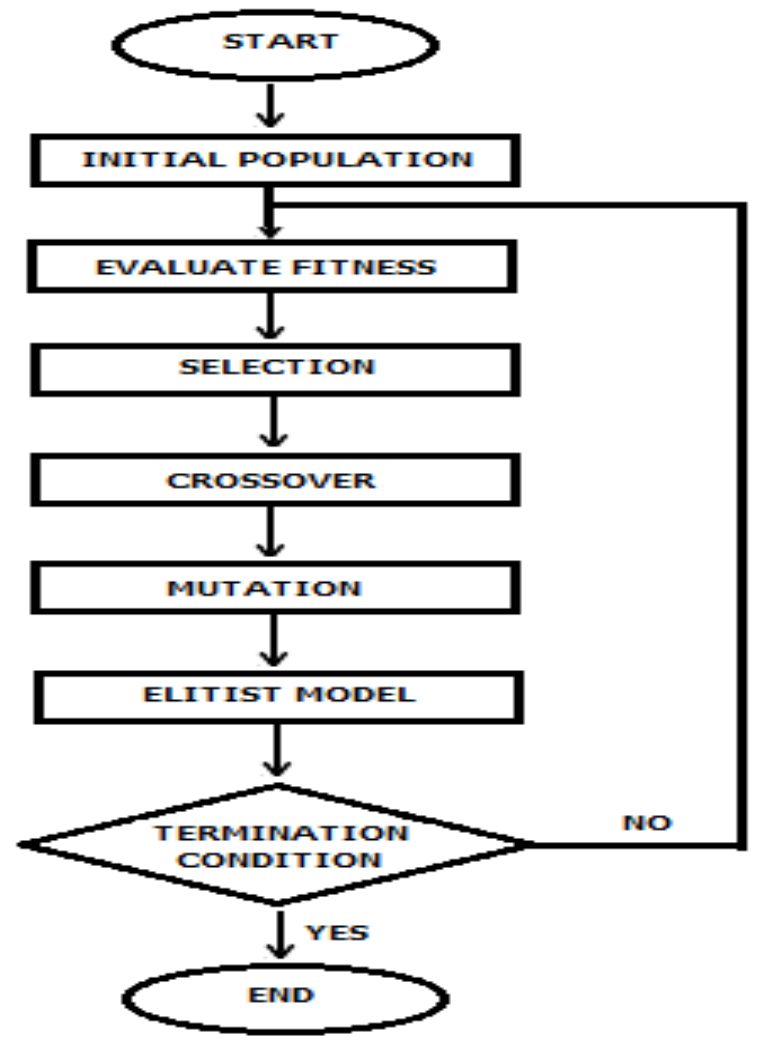

Figure 3. Operation flowchart for the genetic algorithm

Table 1. GA Parameters

\begin{tabular}{|c|c|}
\hline Parameters & Values \\
\hline Population size & 10 \\
\hline Mutation rate & 0.8 \\
\hline Crossover rate & 0.5 \\
\hline Generation number & 100 \\
\hline Tolerance & 0.001 \\
\hline
\end{tabular}

\section{Calibration of the model}

Since we have only limited experimental data, we used seven days in May and July to test this model. The calibration is carried out in two steps:

1. Identify twelve actual greenhouse parameters by GA for each data sequence.

2. Validation of model calibrated from two data sequences.

Comparisons between actual measurements inside the greenhouse and the MIMO model are exposed in the Figure 4, 5, 6 and Figure 7. The final optimum parameters system settings are enumerated in the (Table 2) [21]. 


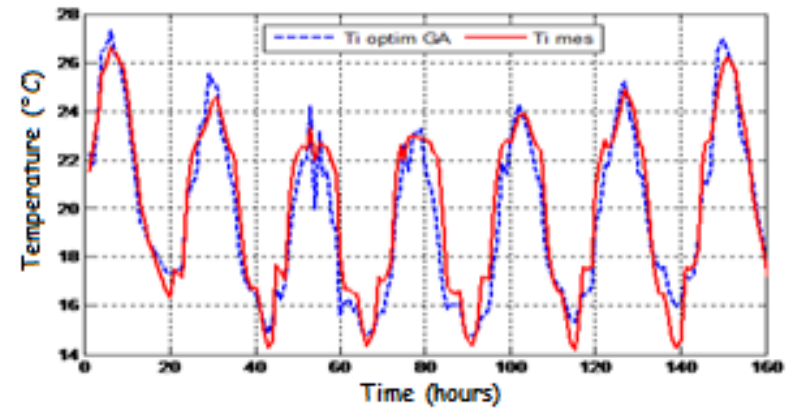

Figure 4. Plots of measured and estimated temperature for seven days of May month

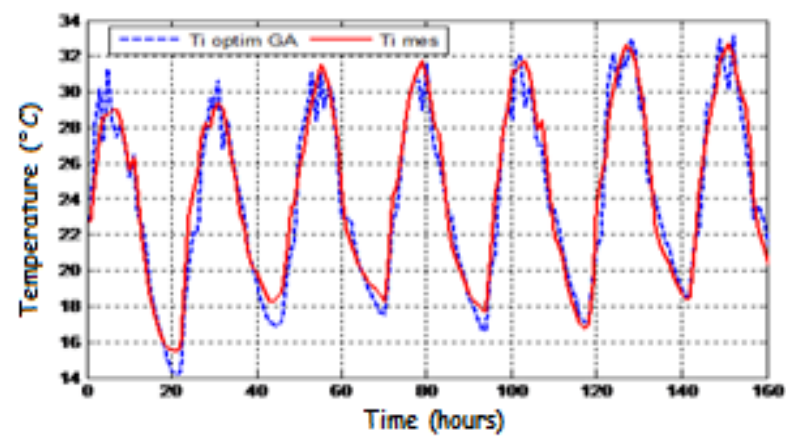

Figure 5. Plots of measured and estimated temperature for seven days of July month

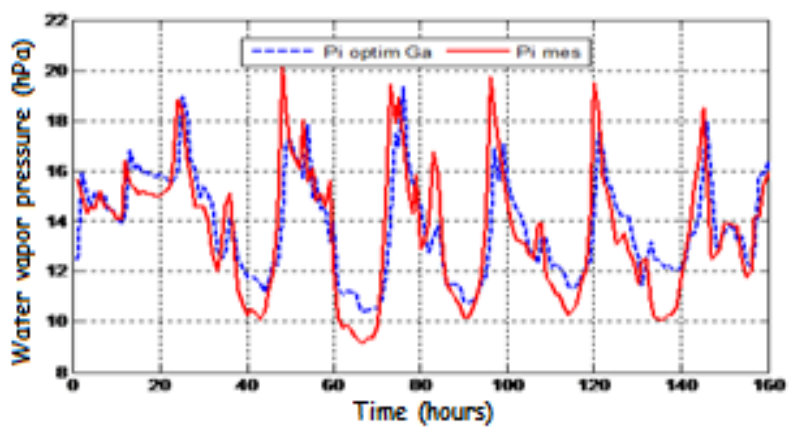

Figure 6. Plots of measured and estimated vapor pressure for seven days of May month

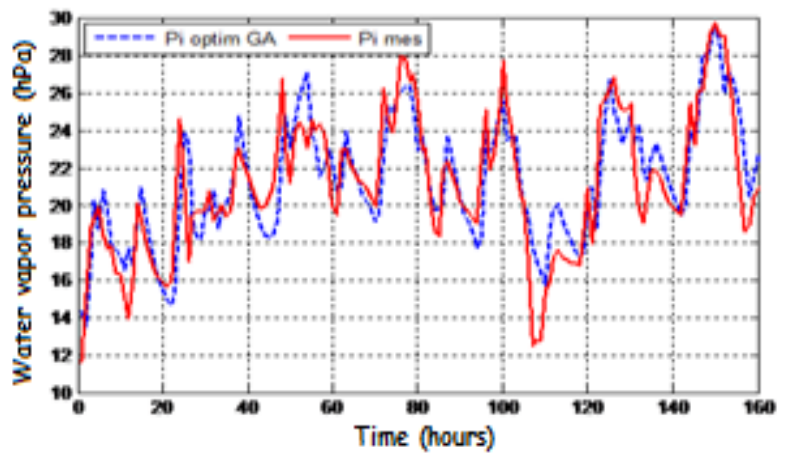

Figure 7. Plots of measured and estimated vapor pressure for seven days of July month 
Table 2. Parameters values of the greenhouse model

\begin{tabular}{|c|c|c|}
\hline Parameters & $\begin{array}{c}\text { Values of } \\
\text { May }\end{array}$ & $\begin{array}{c}\text { Values of } \\
\text { July }\end{array}$ \\
\hline$s_{0}\left(\mathrm{~m}^{2}\right)$ & 0.6215 & 0.0856 \\
\hline$d_{0}\left(\mathrm{~m}^{3} \mathrm{~s}^{-1}\right)$ & 0.5347 & 0.3286 \\
\hline$\beta()$. & 0.0834 & 0.0277 \\
\hline$\alpha()$. & 0.3395 & 0.3135 \\
\hline$h\left(\mathrm{Wm}^{-2} \mathrm{~K}^{-1}\right)$ & 7.0225 & 5.5673 \\
\hline$h^{\prime}\left(\mathrm{Wm}^{-2} \mathrm{~K}^{-1}\right)$ & 3.9555 & 1.6782 \\
\hline$C_{m}\left(\mathrm{Jm}^{-2} \mathrm{~K}^{-1}\right)$ & 187.5983 & 21.431 \\
\hline$C_{v}\left(\mathrm{Jm}^{-2} \mathrm{~K}^{-1}\right)$ & 3.4374 & 4.6873 \\
\hline$B\left(\mathrm{Wm}^{-2} \mathrm{hPa} a^{-1}\right)$ & 3.2626 & 4.2137 \\
\hline$T_{m 0}\left({ }^{\circ} \mathrm{C}\right)$ & 19.5271 & 19.1304 \\
\hline$T_{v 0}\left({ }^{\circ} \mathrm{C}\right)$ & 13.0403 & 14.9595 \\
\hline$P_{i 0}(\mathrm{hPa})$ & 12.4786 & 14.4113 \\
\hline
\end{tabular}

\section{PI SLIDING MODE CONTROL TECHNIQUE Design of PI Controller}

The role of monitors is to minimize the error between the actual output, to be controlled, and the desired output, called reference signal. This error can be given by the following expression:

$$
e(t)=y_{r}(t)-y(t)
$$

where;

- $e(t)$ is the error signal,

- $y_{r}(t)$ and $y(t)$ represent respectively the tracking reference signal and the outing of the system.

The PI controller is about the most common and useful algorithm in control system engineering. It is the standard and proven solution for the most industrial use like greenhouse system [5, 6, 23]. The major reason is its relatively simple diagram that can be easily interpreted and implemented in practice range. A representative block of those controllers engages two constituent the proportional $\left(k_{p}\right)$ and integral $\left(k_{i}\right)$ gains. Proportional value specifies the reaction to the actual error and the integration value defines the reaction founded on the total recent errors. The mathematical description of its control law is generally described in the corresponding parallel form by equation [24].

$$
u(t)=k_{p} e(t)+k_{i} \int_{0}^{t} e(\tau) d \tau
$$

\section{Design of Sliding Mode Control}

The SMC control is a typical nonlinear control strategy, which influences the system performances by continuous commutation of the controlled variable according to the actual status of the known system state and thus causes the trajectory to displace on a predefined sliding surface $[25,26]$. SMC controllers are designed to conduct the system states into a particular state space surface, named sliding surface. When the sliding surface is achieved, sliding mode control keeps the states on the nearby neighborhood of the sliding surface. Subsequently the sliding mode control is a two section controller design. The initial part suggests the design of a sliding surface. The second concerns the decision of a control law that will make the switching surface attractive for the state of the system 
[27].In this first part it is desired to have the output signal $y(t)$ converge to and follow a reference signal $y_{r}(t)$.With this aim we can define a tracking residual signal $e(t)$ between $y_{r}(t)$ and $y(t)$.

The typical form of the general equation for determining the sliding surface $(\sigma)$ that converts a variable to its desired value is [25]:

$$
\sigma=\left(\frac{d}{d t}+\lambda\right)^{k} e
$$

The selection of the positive coefficient $\lambda$ is practically arbitrary, and determines the only pole of the resulting "reduced dynamics" of the system when in sliding. The integer coefficient $k$ takes the expression $r-1$, where $r$ is the relative degree of the model. The relative degree is $r=1$ then; the switching function can be formulated as:

$$
\sigma=e
$$

The second part is to find a control action that steers the system trajectories into the sliding manifold, that is to say, the control is able to direct the variable to zero in small time. The important goal is to compel the residual to zero, so that the derivative of switching surface is zero.

$$
\frac{d}{d t}(\sigma)=0
$$

This means that the controlled variable has reached the desired value. Where $e(t)$ become equal to zero and $\sigma$ reaches a constant value. The control law of the SMC strategy is given by the sum of continuous $\left(u_{c}(t)\right)$ and discontinuous $\left(u_{d}(t)\right)$ parts.

$$
u(t)=u_{c}(t)+u_{d}(t)
$$

There are diverse methods founded on the sliding control approach:

- First order SMC control.

- High order SMC control.

In the model equations we have the relative degree $r=1$, then we choose the first order SMC control. The control is discontinuous across the manifold $\sigma=0$.

$$
u=-U \operatorname{sgn}(\sigma)
$$

In steady state, $U$ is a positive constant of significant value. This last will switch to a high frequency between the values $u=U$ and $u=-U$. High frequency discontinuous switching control promotes chattering phenomenon. To fix chattering at the cost of a loss of robustness smoothed implementations of sliding control procedures have been recommended where the discontinuous "sign" term is supplanted by a continuous smooth approximation.

$$
u=-U \cdot \operatorname{sat}(\sigma, \varepsilon)=-U \frac{\sigma}{|\sigma|+\varepsilon}
$$

or

$$
\mathrm{u}=-\mathrm{U} \cdot \tan (\sigma, \varepsilon)
$$

Where $\varepsilon$ a small positive design is constant also called tuning parameter used to reduce chattering phenomenon. 
The combined sliding mode control and PI controller law will be:

$$
\begin{gathered}
u(t)=u_{P I}(t)+u_{S M C}(t) \\
u(t)=k_{p} e(t)+k_{i} \int_{0}^{t} e(\tau) d \tau-\mathrm{U} \frac{\sigma}{|\sigma|+\varepsilon}
\end{gathered}
$$

The fundamental layout of closed loop control system with GA PISMC controller of greenhouse is marked in Figure 8. The saturation limits are for the heating of the air between 0 and $300 \mathrm{Wm}^{-2}$ and for the openings they are between 0 and $35 \mathrm{~m}^{2}$.

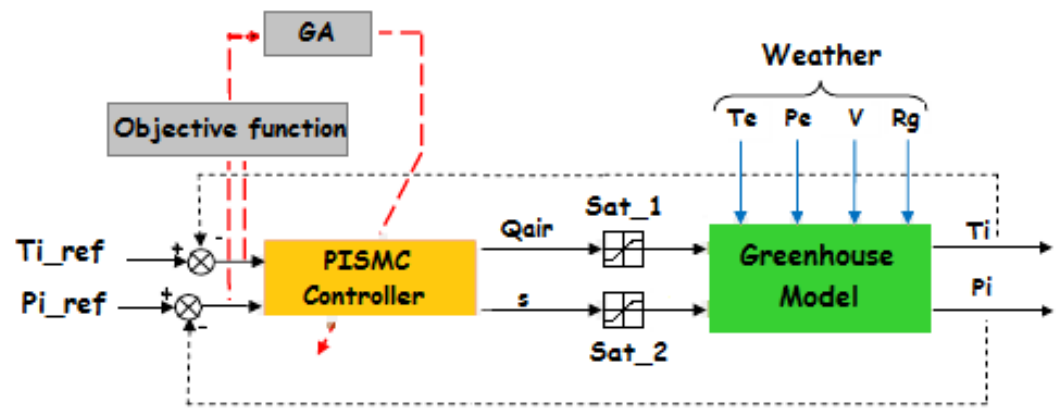

Figure 8. Structure of GA PISMC control

The reactions loops are controlled using PISMC law. Feedback is very significant in systems in order to reach a set point tracking irrespective of disturbances or any variation in any form.

\section{SIMULATION RESULTS}

A genetic algorithm based PISMC controller for the greenhouse system, including the mean performance indices (MSE) is carried out and simulated results are plotted. In order to illustrate the efficiency of the PISMC scheme, a simulation study implemented in the Matlab/Simulink environment, has been carried out using the above nonlinear calibrated equations of greenhouse. The controlled outputs variables $\left(T_{i}, P_{i}\right)$ are constrained to track the optimal references $\left(25^{\circ} \mathrm{C} / 20 \mathrm{hPa}\right)$ of daytime and nocturnal optimal references $\left(14^{\circ} \mathrm{C} / 13 \mathrm{hPa}\right)$ during the night. Block diagram of the PI sliding mode control is implemented in the Matlab/Simulink and displayed in Figure 9.

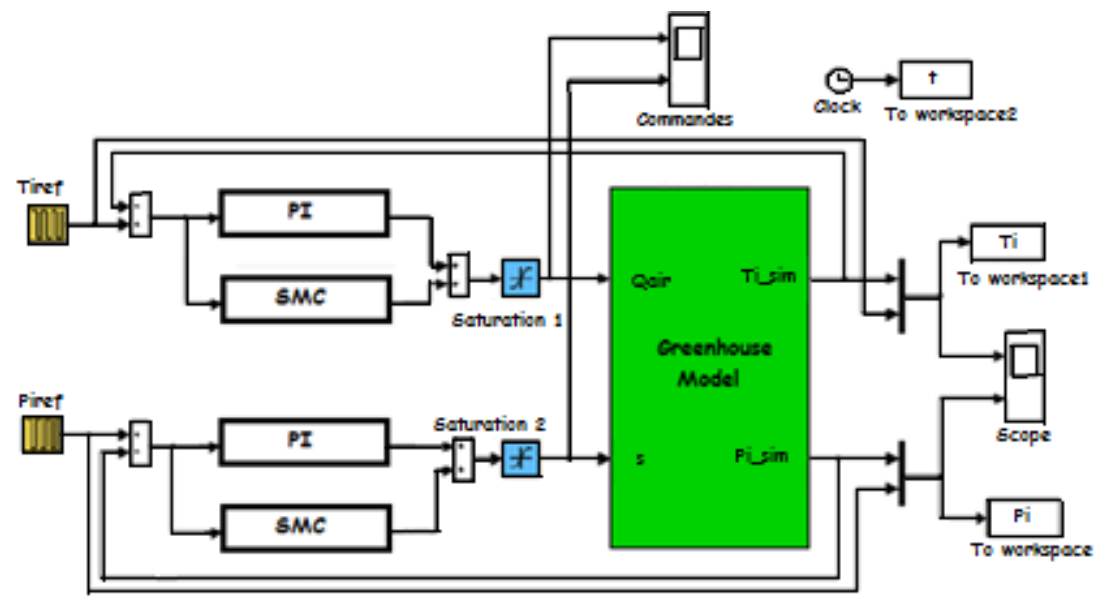

Figure 9. Simulink model of the PISMC controller 
To test this control method we combine SIMULINK module and Matlab functions where, the main blocs are realized in SIMULINK and the optimized PISMC controller is predicted using Matlab file program function. Figure 10 and Figure 11 indicate the ability of the system to track the desired inputs for the internal temperature and water vapor pressure respectively. Minimal errors are exposed in Figure 12 and Figure 13. The minimization of the fitness function leads to get the following optimal gains of PISMC controller (Table 3):

Table 3. Parameters values of GA PISMC

\begin{tabular}{|c|c|c|}
\hline Parameters & $\begin{array}{c}\text { PISMC Values } \\
\text { of Ti loop }\end{array}$ & $\begin{array}{c}\text { PISMC Values } \\
\text { of Pi loop }\end{array}$ \\
\hline$K p$ & 07.8675 & 0.0059 \\
\hline$K i$ & 250.1285 & -07.9875 \\
\hline$\lambda$ & 0.8512 & 0.2582 \\
\hline$U$ & 0.1285 & 0.0250 \\
\hline$\varepsilon$ & 0.2552 & 0.0075 \\
\hline
\end{tabular}

Figure 14 and Figure 15 illustrates the constrained control signals achieved by the proposed design technique. It is noted that these actuators are weakly solicited, and alternate with each other.

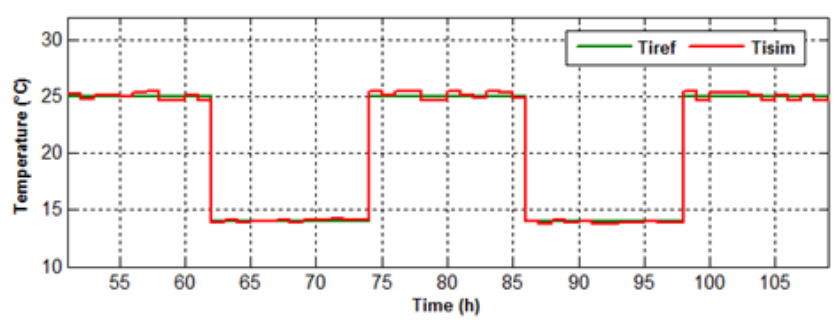

Figure 10. Greenhouse indoor temperature

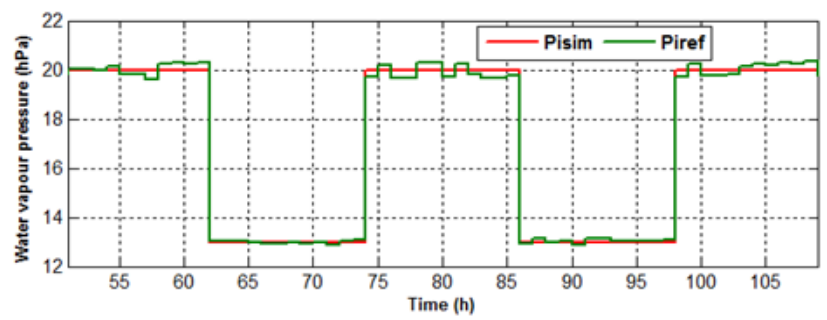

Figure 11. Greenhouse water vapor pressure

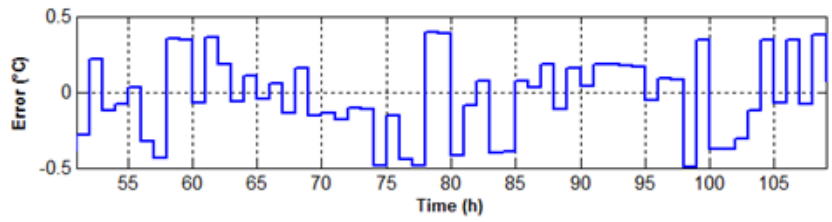

Figure 12. Evolution of the error result between the output (Ti) and desired air temperature 


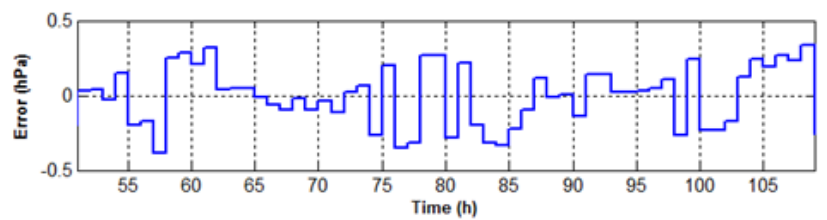

Figure 13. Evolution of the error result between the output $(\mathrm{Pi})$ and desired water vapor pressure

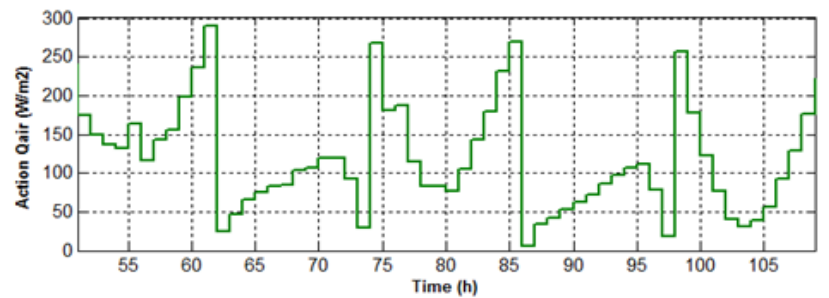

Figure 14. Evolution of the $Q_{\text {air }}$ action

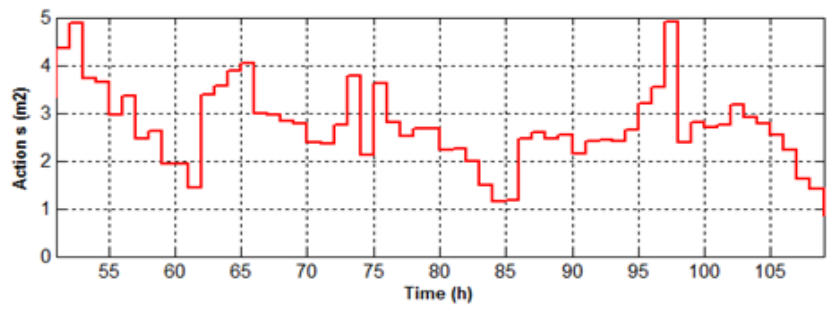

Figure 15. Evolution of the opening action

Simulation results during three days are depicted in the above figures. Through these graphs the PISMC controller gives good tracking performances.

\section{CONCLUSION}

The identification and control of the MIMO indoor microclimate greenhouse is presented in this paper. A predicted thermohydric model was estimated and calibrated with experimental data measures. The resulting analytical dynamic model is well suited for PISMC control, which is, in principle, much better with respect to indoor climate and energy saving than conventional controllers. In this control technique the SMC algorithm, emphasizing on the benefits of PI control law, are used to control the microclimate MIMO greenhouse. GA based PISMC controller tuning has been designed and applied to the greenhouse process. From the simulation studies, we infer that optimized controller coefficients obtained by the use of this algorithm with MSE as cost indices have achieved satisfactory set point tracking. From the simulation, it is clear that PISMC exhibits good performances, and it is suitable for MIMO control loops that experience loop interactions. Results have also shown that in spite of limits on vent opening $(s)$ and air heating $\left(Q_{\text {air }}\right)$ the PISMC robustness is confirmed.

\section{NOMENCLATURE}

$A l \sqrt{C} \quad$ Natural ventilation model factor (.).

$A \quad$ Coefficient of the model of transpiration (.).

$B \quad$ Coefficient of the model of transpiration $\left(\mathrm{Wm}^{-2} \mathrm{hPa}^{-1}\right)$.

$C_{l} \quad$ Equivalent thermal capacity of the water vapor of the air $\left(\mathrm{JhPa}^{-1} \mathrm{~m}^{-2}\right)$,

$C_{m} \quad$ Soil thermal capacitor $\left(\mathrm{Jm}^{-2} \mathrm{~K}^{-1}\right)$. 


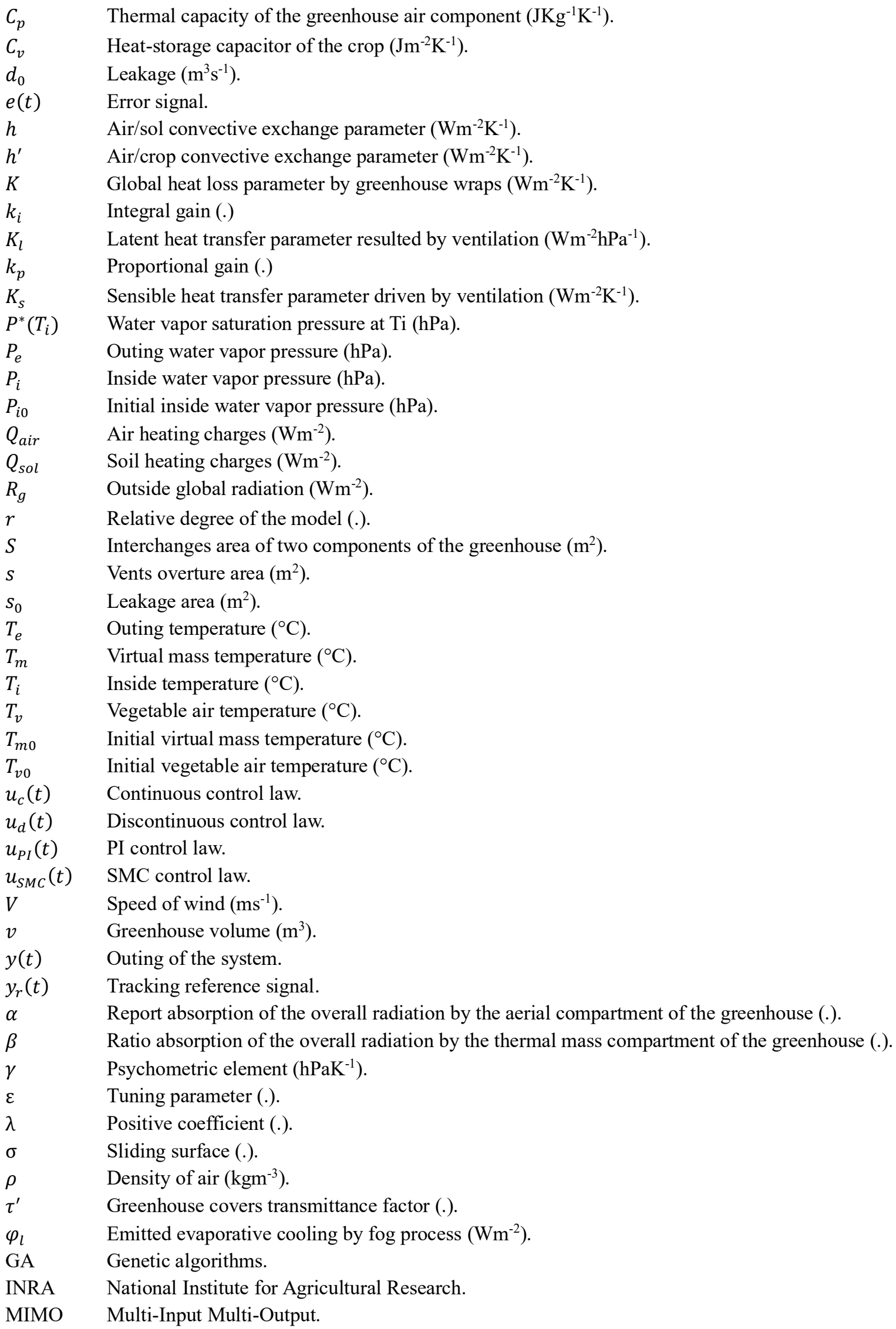


Journal of Thermal Engineering, Research Article, Vol. 6, No. 3, pp. 313-326, April, 2020

$\begin{array}{ll}\text { MSE } & \text { Mean square error. } \\ \text { PI } & \text { Proportional Integral. } \\ \text { PISMC } & \text { PI sliding mode control. } \\ \text { SMC } & \text { Sliding mode control. }\end{array}$

\section{REFERENCES}

[1] Revathi S, Sivakumaran N. Fuzzy Based Temperature Control of Greenhouse. IFAC PapersOnLine 2016; Vol 49, Issue 1, 549-554. https://doi.org/10.1016/j.ifacol.2016.03.112.

[2] Emelyanov S. V. Variable structure control systems. Nauka, Moscow; 1967.

[3] Blasco X, Martínez M, Herrero J.M, Ramos C, Sanchis J. Model-based predictive control of greenhouse climate for reducing energy and water consumption. Comput Electron Agr 2007; 55:49-70. https://doi.org/10.1016/j.compag.2006.12.001.

[4] Draoui B, Bounaama F, Boulard T, Bibi-triki N. In-situ Modelization of a Greenhouse Climate Including Sensible Heat, Water Vapor and CO2 Balances. EPJ Web of conferences 2013; 45.01023. https://doi.org/10.1051/epjconf/20134501023.

[5] Manonmani A, Thyagarajan T, Elango M, Sutha S. Modelling and control of greenhouse system using neural networks. Transactions of the Institute of Measurement and Control 2016; Vol 40, Issue 3, 918-929 https://doi.org/10.1177/0142331216670235.

[6] Herrero J.M, Blasco X, Martínez M, Ramos C, Sanchis J. Non-linear robust identification of a greenhouse model using multi-objective evolutionary algorithms. Biosyst Eng 2007; Vol 98, Issue 3, 335-346. https://doi.org/10.1016/j.biosystemseng.2007.06.004.

[7] Patil S.L, Tantau H.J, Salokhe V.M. Modelling of tropical greenhouse temperature by auto regressive and neural network models. Biosyst Eng 2008; 99:423-431. https://doi.org/10.1016/j.biosystemseng.2007.11.009.

[8] Cheng M, Yuan H, Zhang M, Cheng M. The Research of Control Method of Greenhouse Based on Global Variable Prediction Model. Chem. Eng. Trans. 2016; Vol. 51,277-282. DOI: 10.3303/CET1651047.

[9] Trabelsi A, Lafont F, Kamoun M, Enea G. Fuzzy identification of a greenhouse. Appl. Soft Comput. 2007; Vol 7, Issue 3, 1092-1101. https://doi.org/10.1016/j.asoc.2006.06.009.

[10] Draoui B. Caractérisation et analyse du comportement thermo-hydrique d'une serre horticole. Thèse de Doctorat de l'université de Nice-Sophia Antipolis, France;1994.

[11] Boulard T, Draoui B, Neirac F. Calibration and validation of a greenhouse climate control model. Acta Hortic 1996; (ISHS), 406, 49-62. https://doi.org/10.17660/ActaHortic.1996.406.4.

[12] Boulard T, Baille A. A simple greenhouse climate control model incorporating effects on ventilation and evaporative cooling. Agr Forest Meteorol 1993; 65, pp. 145-157. https://doi.org/10.1016/0168-1923 (93)90001-X.

[13] Rodriguez F. Modeling and hierarchical control of greenhouse crop production (in Spanish). PhD thesis. University of Almeria, Spain; 2002.

[14] Boulard T, Wang S. Greenhouse crop transpiration simulation from external climate conditions. Agric For Meteorol. 2000; Vol 100, Issue 1, 25-34. https://doi.org/10.1016/0168-1923(93)90001-X.

[15] Ghoumari M.E, Tantau H, Serrano J. Non-linear constrained mpc: real-time implementation of greenhouse air temperature control. Comput Electron Agr 2005; 49, 345-356. https://doi.org/10.1016/j.compag.2005.08.005.

[16] Moughli H. Elaboration d'un modèle réduit d'ordre deux du bilan d'énergie d'une serre, Identification avec Optimisation des paramètres. Mémoire de magister en physique énergétique;2007.

[17] Bounaama F, Draoui B. Greenhouse environmental control using optimized MIMO PID technique. Sens Transduc 2011; 133:44-52.

[18] HollandJ.H. Adaptation in Natural and Artificial System. Ann Arbor, the University of Michigan Press; 1975.

[19] Salami M, Cain G. An Adaptive PID Controller Based on Genetic Algorithm Processor. Genetic Algorithms in Engineering Systems: Innovations and Applications 1995; 12-14 September, Conference Publication No. 
414, IEE. https://doi.org/10.1049/cp:19951030.

[20] Yusuf L.A, Magaji N. GA-PID Controller for Position Control of Inverted Pendulum. Adaptive Science \& Technology (ICAST), IEEE 6th International Conference on 29-31 Oct. 2014. https://doi.org/10.1109/ICASTECH.2014.7068099.

[21] Lammari K, Bouaama F, Draoui B, Mrah B, HaidasM. GA Optimization of the Coupled Climate model of an order two of a Greenhouse. Energy Procedia 2012; 18, 416-425. https://doi.org/10.1016/j.egypro.2012.05.053.

[22] Dai C, Yao M, Xie Z, Chen C, Liu J. Parameter optimization for growth model of greenhouse crop using genetic algorithms. Appl Soft Comput 2009; 9:13-19. https://doi.org/10.1016/j.asoc.2008.02.002.

[23] Fourati F, Chtourou M. A greenhouse control with feed-forward and recurrent neural networks . Simulat. Model. Pract. Theor. 2007; Vol 15, Issue 8, 1016-1028. https://doi.org/10.1016/j.simpat.2007.06.001.

[24] Taylor C.J, Leigh P, Price L, Young P.C, Vranken E, Berckmans D. Proportional-integral-plus (PIP) control of ventilation rate in agricultural buildings. Control Eng Pract 2004; 12, $225-233$. https://doi.org/10.1016/S0967-0661(03)00060-1.

[25] Slotine J.J.E, Li W, Applied Nonlinear Control. Prentice-Hall; 1991.

[26] Bandyopadhyay B, Deepak F,KimK.S. Sliding Mode Control Using Novel Sliding Surfaces. Springer; 2009.

[27] Utkin V.I. Variable Structure Systems with Sliding Modes. IEEE Trans. Autom. Control. 1977; 22, 2, 212222. http://dx.doi.org/10.1109/tac.1977.1101446. 